\title{
A description of verbal and gestural communication during postictal aphasia
}

Alexia Fasola, F.-Xavier Alario, Marion Tellier, Bernard Giusiano, Carlo Alberto Tassinari, Fabrice Bartolomei, Agnès Trébuchon

\author{
Alexia Fasola \\ Institute of Language, Communication and the Brain (ANR-16- CONV-0002) - ILCB, Aix-Marseille \\ Univ., France \\ E-mail address: alexia.fasola@univ-amu.fr \\ F.-Xavier Alario
}

Aix Marseille Univ, CNRS, LPC, Marseille, France

Marion Tellier

Aix Marseille Univ, CNRS, LPL, Aix-en-Provence, France

Bernard Giusiano

Aix Marseille Univ, INSERM, INS, Inst Neurosci Syst, Marseille, France

Carlo Alberto Tassinari

University of Bologna, Italy

Fabrice Bartolomei

Aix Marseille Univ, INSERM, INS, Inst Neurosci Syst, Marseille, France

Agnès Trébuchon

Aix Marseille Univ, INSERM, INS, Inst Neurosci Syst, Marseille, France

Acknowledgements: This work, carried out within the Labex BLRI (ANR-11-LABX-0036) and the Institut Convergence ILCB (ANR-16-CONV-0002), has benefited from support from the French government, managed by the French National Agency for Research (ANR) and the Excellence Initiative of Aix-Marseille University (A*MIDEX).

Highlights:

- Patients with drug-refractory epilepsy tested during transient postictal states

- Language and communication skills assessed as speech flow and gesture rate changes

- Increase in rhythmic gesture rates with decreased verbal flow

- No clear distinction between patients with left temporal and frontal lobe seizures in this small sample

Keywords: Language impairment; co-speech gestures; epilepsy; postictal testing 
Fasola et al.

\section{Abstract}

Patients suffering from drug-resistant temporal lobe epilepsy show substantial language deficits (i.e anomia) during their seizures and in the postictal period (postictal aphasia). Verbal impairments observed during the postictal period may be studied to help localizing the epileptogenic zone. These explorations have been essentially based on simple tasks focused on speech, thus disregarding the multi-modal nature of verbal communication, particularly the fact that, when speakers want to communicate, they often produce gestures of various kinds. Here, we propose an innovative procedure for testing postictal language and communication abilities, including the assessment of co-speech gestures. We provide a preliminary description of the changes induced on communication during postictal aphasia.

We studied 21 seizures that induced postictal aphasia from 12 patients with drugrefractory epilepsy, including left temporal and left frontal seizures. The experimental task required patients to memorize a highly detailed picture and, briefly after, to describe what they had seen, thus eliciting a communicative meaningful monologue. This allowed comparing verbal communication in postictal and interictal conditions within the same individuals. Co-speech gestures were coded according to two categories: "Rhythmic" gestures, thought to be produced in support of speech building, and "illustrative" gestures, thought to be produced to complement the speech content.

When postictal and interictal conditions were compared, there was decreased speech flow along with an increase of rhythmic gesture production at the expense of illustrative gesture production. The communication patterns did not differ significantly after temporal and frontal seizures, yet they were illustrated separately, owing to the clinical importance of the distinction, along with considerations of inter-individual variability.

A contrast between rhythmic and illustrative gestures production is congruent with previous literature in which rhythmic gestures have been linked to lexical retrieval processes. If confirmed in further studies, such evidence for a facilitative role of co-speech gestures in language difficulties could be put to use in the context of multimodal language therapies. 
A description of verbal and gestural communication during postictal aphasia

\section{Introduction}

Patients with drug-refractory epilepsy show substantial cognitive deficits in verbal memory, naming or spontaneous speech between seizures $[1,2]$. In addition, during seizures themselves, and during postictal periods, these deficits can be more pronounced [3].

Postictal state is defined as transitory and reversible disturbances comprised between the end of the seizure (ictal state) and the return to initial behavior (interictal state). Postictal states have received less attention than ictal states in the field of clinical epileptology research. However, there is evidence to suggest that postictal states can provide clues regarding the organization of epileptogenic zones [4, 5, and 6]. Postictal language assessments have been proposed to help lateralize the epileptogenic zone (EZ) in clinical investigations (reviewed in [7]). Because postictal language deficits are transient, they afford to study communication patterns within the same individual, by contrasting postictal performance against interictal "baseline" performance. Previous studies exploring the different dynamics of language skill recovery during postictal states have shown that language lateralization is an important moderating factor. A greater postictal language recovery delay is observed in patients with seizures occurring in the hemisphere specialized for language than in those for which they occur in the contralateral hemisphere. Other studies revealed consistent speech prosody changes in the postictal states of patients with temporal lobe seizures in the hemisphere non-specialized for language. Postictal language testing has also been explored to address the distinction between frontal and temporal lobe seizures. Goldberg-Stern et al. (2004) observed prolonged postictal language deficits when seizures spread from the frontal lobe to a specialized temporal lobe [8]. This observation was infrequent when seizures were confined to the specialized frontal lobe.

This literature hints at the usefulness of postictal language testing for clinical purposes, suggesting that a better understanding of postictal language skills could provide cues about the localization of the EZ, for example to help identifying the hemisphere specialized for language, or to tease apart frontal from temporal EZ in a dominant hemisphere. In the current paper, we explore whether a nonverbal language features as co-speech gestures is modified during postictal language impairments.

Gestures contribute to the multimodal nature of language communication which, in addition to speech, may involve co-speech gestures, gaze orientation, posture, and other features, all of which give complementary information about the content of the transmitted message. Co-speech gestures are defined as hand movements only produced during speech, with an overlap in meaning with the speech content [9]. The link between speech and coFasola et al. 
speech gestures has been mostly studied in healthy speakers $[9,10,11]$, but it can also be fruitfully investigated in verbal impairments like aphasia $[12,13,14,15,16]$. Indeed, gestures are often used in daily life in the context of verbal difficulties.

In the linguistic literature, various theoretical frameworks about the link between speech and co-speech gestures have been proposed (Figure 1). First, the Growth Point Theory (GPT) proposes that the generation of a (multimodal) utterance is based on a holistic representation, termed a "growth point" [17]. This growth point contains both "imagistic" information, which is turned into gestures, and "symbolic" information, which is turned into speech. In this theory, purely verbal aphasic impairments may reflect the incorrect development of the speech part of the holistic representation, while the imagistic part is appropriately processed. This would result in appropriate gestures being produced along an incomplete verbal utterance [9, 17, 18]. Alternatively, the "lexical access model" [19] suggests that there are primary "iconic" gestures (also called lexical gestures) which are produced not only to convey imagistic information, but also to facilitate the speaker-internal process of word form retrieval. In this view, the motor planning of a lexical gesture is a cross-modal primer for word form retrieval $[18,19]$. Finally, other theories, inspired by the "embodied cognition" framework, propose that gestures are generated from the same processes that also generate practical actions. Kita et al. (2017) thus proposed that co-speech gestures affect cognitive processes in four ways [20]: They activate spatial information which pertains to the semantic features of an item; they maintain visuo-spatial imagery; they ease packaging spatio-motoric information for verbal encoding; finally, co-speech gestures may contribute to reduce cognitive load for creating an utterance. In this theory, gestures drive speech and thought.

In sum, there are broadly two main accounts of the relationship between co-speech gestures, speech, and thought in the literature. The first account postulates a unique communication system including gesture and speech (Figure 1, shades of blue elements). The second account proposes that there are two communication systems with a supporting role of gesture when speech is impaired (Figure1, red elements). The debates on the nature of this relationship are still ongoing, and our study does not aim to adjudicate between these positions. However, we will use this general framework when interpreting our observations. Part of these debates has concerned the disparity of gesture classifications and experimental designs that are used in studies on aphasic communication patterns. In the current research, we chose to categorize co-speech gesture based on McNeill's well-established classification, which we slightly adapted to our needs (see Methods and Table3). 
Along these functional cognitive models, the neural bases of gesture processing have also been explored. Regarding gesture comprehension, a meta-analysis of functional magnetic resonance imaging (fMRI) studies concludes to the involvement of three neural networks in gesture processing. A perceptual-motor network, shared with the network involved in action observation, is required for gesture processing. In addition, for gestures that convey meaning such as co-speech gestures, neural activations linked to conceptual processing have been reported in posterior middle temporal gyrus and in pars triangularis of the inferior frontal gyrus. Finally, activations observed in BA47, insula, and putamen during gesture comprehension have been linked to the expression of the social and emotional components of gestures [21]. In contrast to the sizeable body of research available on the neural basis of gesture observation and comprehension, there are very few studies on the neural basis of cospeech gesture production. Perhaps most prominently, Marstaller and collaborators explored this issue using magneto-encephalography (MEG). Their research sheds light on the role of Broca's area in the coordination between speech and co-speech signals and on the implication of medial temporal cortex in binding of information in memory during speech and co-speech gestures production [22, 23].

As pointed out above, postictal communication deficits could provide additional valuable information about the localization of the EZ in a specialized hemisphere for language. To the best of our knowledge, the issue of co-verbal gestures has not been investigated in patients with epilepsy. In the current study, we explored, for the first time, whether co-speech gestures would be transiently affected during postictal language impairments. Our hypothesis was that when speech flow decreases in postictal versus interictal conditions, we would also observe a modification in the pattern of co-speech gesture production. We further expected that postictal communication patterns might be different between temporal and frontal seizures. Based on previous MEG studies about gesture's production [22, 23], a disorganization of the frontal lobe function should impair the coordination between speech and co-speech gesture, leading to a decrease of speech gesture production or an increase of the production of gestures without speech overlap (i.e. gestures that are not co-speech gestures). An impairment in the temporal lobe should lead to deficits in speech and co-speech gesture retrieval with the occurrence of gestures which ease word retrieval.

\section{Methods}

\subsection{Patients and seizures}

Fasola et al. 
Fasola et al.

We tested 12 patients with drug-refractory epilepsy (6 females), all native speakers of French. All patients signed an informed consent form prior to participation. This study was approved by the Institutional Review Board of the French Institute of Health (IRB00003888, FWA00005831). The patients had a mean age of 36 years and intelligence quotient (IQ) above 80 . Eight patients were right-handed, with left hemisphere language dominance. The patients underwent video-electroencephalography (EEG) or videosetreoelectroencephalography (SEEG) following complete or partial withdrawal of antiepileptic drugs during a usual period of 4 to 10 days in order to record several of the patient's habitual seizures, for presurgical diagnostic purposes. For the current study, they were tested collaterally to those diagnostic procedures.

We gathered data during a total of 21 seizures that induced postictal language deficits. We excluded one patient with parieto-premotor epilepsy that may have severe motor deficits in postictal phases. In addition, we chose to not report the results of one patient with ambiguous EZ e.g. seizures not suitably classified as left temporal lobe epilepsy because of fast propagation of seizures into the right hemisphere, or seizures distributed both in temporal and frontal lobes. In total, we thus report the features of 19 seizures from 10 patients whose heterogeneous epilepsy types are reflected in lesion topography and MRI results (Table 1). Seizure duration (between 60 and $180 \mathrm{~s}$; Table 2) was defined as the period between the first epileptic manifestations and the end of the ictal period, as assessed by an expert neurologist (AT). Some patients lost consciousness during their seizures (7 patients), which may be linked with the propagation zone [24].

We highlight that the organization of the EZ was defined following standard clinical practice, not the analysis of speech or gestures. The clinical procedure included the analysis of electro-clinical correlation recorded in video-SEEG or in video-EEG. Additional data such as morphological data (MRI) and functional metabolic data (positron emission tomography) were also taken into account. Two types of seizure organization were distinguished on the basis of their topology. Five of them originated from left fronto-insular system; we refer to them as left frontal lobe seizures (LF). Fourteen started from left temporal lobe; we refer to them as left temporal lobe seizures (LT).

\subsection{Postictal testing and analysis}

\subsubsection{Experimental design and procedure}

The patients were tested in interictal and in postictal conditions. Interictal conditions were defined as periods far from seizures (i.e. at least a few hours after the last seizure). 
Postictal were defined as the moment between the end of the seizure (ictal state) and the return to initial behavior (interictal state). To assess the language function during this period naming task, oral and written comprehension tasks, repetition tasks, bucco-facial praxia tasks, and reading have been done. Our testing did not start until the patient was able to name correctly 3 items in the naming task, it varies from 2.5 to 15 min between patients (Table2, column Testing delay). We called postictal conditions the moment of the beginning of our testing. This allowed us to exclude seizures inducing apraxic impairments during postictal states, which would have complicated the interpretation of the results, especially for LF seizures which may disorganize motor abilities independently of language or communication skills. Testing delay is the duration between the beginning of the seizure and the start of postictal testing, as assessed by the analysis of video records.

Once the clinical assessment was finished, the experimental protocol started. Its main purpose was to elicit multimodal communication involving speech and co-speech gestures. The task consisted of memorizing a given picture for $30 \mathrm{~s}$, then providing a verbal description that lasted around $3 \mathrm{~min}$. The task was performed with two different pictures of complex scenes in which there were different characters, interactions, objects, etc. Typical communication tasks require the description or re-description of a complex stimulus are often used to elicit gesture production in research with healthy speakers [9, 25, 26, 27]. Often the stimulus is a cartoon or comic strip; here, we used a single static picture to reduce the duration of testing, which was constrained by the transient nature of postictal states. In the interictal condition, the patients were successively tested with both pictures; in the postictal condition of any seizure, patients were presented only one of the pictures.

\subsubsection{Linguistic analyses}

We analyzed video recordings using the software ELAN (EUDICO Linguistic ANnotator; Max Planck Institute for Psycholinguistics, 2002; see Supplementary material 1). We quantified the speech flow in words per second, and identified language disfluencies based on hesitations and interrupted words. Gesture units were defined as the duration from the start of a movement to a return to resting position, to a pause in the movement, or to a change in shape or trajectory [9]. We excluded non-communication gestures (e.g. touching own's face, changing posture or hand position, recreational gestures, etc.) because of their presumed lack of semantic content. Each detected co-speech gesture was classified based on an annotation guide that included eight forms of gestures (Table 3 and Supplementary material 1) [25, 26, $27,28]$, which we classified into two superordinate categories: "illustrative" and "rhythmic". Fasola et al. 
According to this classification, "illustrative" gestures are produced to illustrate the speaker's speech. "Rhythmic" gestures are produced in support of speech building. Inter-rater agreement estimates are a crucial feature in studies about co-speech gestures. We asked 3 raters ( 2 naive and 1 expert in co-speech gesture rating) to code one interictal test of one patient and we computed inter-rater agreement using Cohen's Kappa. The observed values, between 0.44 and 0.58 with $95 \%$ of confident interval, are considered acceptable in the context of 8 co-speech categories $[29,30]$.

\subsection{Statistical analyses}

Speech flow was quantified as the number of words per second. Co-speech gestures were assessed by counting the total number of gestures, then distinguishing the number of gestures in each category (illustrative and rhythmic), and computing gesture frequency as the ratio between the number of gesture in one category and the total number of gestures. We compared these values between postictal and interictal conditions in patients who present seizures from left temporal or left frontal areas.

Using the R software package, we computed regression models to assess the relationship between each variable (speech flow, number of rhythmic or illustrative gestures and frequency of rhythmic or illustrative gestures) with the testing moment (inter or postictal) and localization of seizure as fixed effects, and with seizure as random effect (for example, adapted from the R script: speech flow $\sim$ testing moment * EZ localization + (1|seizure)).

\section{Results}

\subsection{Descriptive statistics}

For every seizure, we report individual speech flow and number of gestures (Table 4). For most of the seizures in patients with EZ in LT, postictal speech flow values were below their corresponding interictal reference value (10/14, Table 4). The variation of number of gestures was more heterogeneous, with only $8 / 14$ postictal values below the reference interictal value.

Figure 2 shows that the relationship between the modification of co-speech gesture production and speech flow when inter- and postictal states are contrasted in temporal seizures. We observed increased rhythmic gesture frequency associated with the reduction of speech flow in postictal versus interictal conditions (Figure 2). We chose to represent the rhythmic gesture category only; with our definition gesture frequency as a proportion of gesture types (see Methods) the illustrative gesture category has the complementary 
frequency distribution (data presented as supplementary material 2). The low number of frontal seizures $(\mathrm{N}=5)$ prevents strong conclusions about the modification of the patients' $(\mathrm{N}=2)$ communication patterns between interictal and postictal conditions (data presented as supplementary material 3).

\subsection{Inferential statistics}

The regression models show that epilepsy type had significant effect on the speech flow (beta $=0.66,95 \%$ CI $[0.18,1.13], \mathrm{p}<.05)$, but there was no significant effect of the testing moment (beta $=0.03,95 \%$ CI $[-0.38,0.45], \mathrm{p}>.1$ ), and no significant interaction between these factors (beta $=-0.26,95 \%$ CI $[-0.75,0.23], \mathrm{p}>.1)$.

The regression models computed on the gesture rate variable show that the effect of testing moment is significant on the frequency of rhythmic gestures (beta $=0.32,95 \% \mathrm{CI}$ $[0.07,0.57], \mathrm{p}<.05)$ ), with no significant effect of epilepsy type (beta $=0.18,95 \%$ CI $[-0.03$, $0.39], \mathrm{p}>.1$ ) and no significant interaction between the two factors (beta $=-0.20,95 \% \mathrm{CI}$ [$0.49,0.10], \mathrm{p}>.1$ ). A low statistical power because of the small and unbalanced number of postictal testing in the LF group may explain some of the non-significant effects.

\subsection{Results summarized}

The descriptive statistics comparing performance in postictal and interictal states revealed a decrease in speech flow along with an increase in the rate of rhythmic gesture production (and the corresponding reduction in the rate of illustrative gestures). This pattern was most clear in LT seizures; there were very few LF seizures, sometimes associated with an increase of speech flow and of rhythmic gestures. The inferential model showed that the decrease in the production of rhythmic gestures production was significant, irrespective of epilepsy type.

\section{Discussion}

Communication through language is a multimodal skill including posture, gaze, facial expressions and co-speech gestures. We thus hypothesized that a more "global" analysis of the language impairment during the postictal state may show systematic patterns that would in turn provide clues about seizure organization.

In the central comparison between postictal and interictal conditions, we observed a significant increase of rhythmic gesture production, along with a decrease in the speech flow. In patients with LT (data depicted on Figure 2), decreased speech flow is congruent with previous evidence of language impairment and in lexical access during postictal periods [7, Fasola et al. 
31]. We also observed dissociation between the types of co-speech gestures produced. The interactions with group (i.e. LT vs LF) were not significant. The low and unbalanced number of observations, due to the very specific circumstances of testing, probably compromise some of the statistical power. The observation of a significant effect of the testing moment on gesture production, irrespective of EZ, indicates a sensibility of co-speech gesture production linked to the occurrence of the seizure; this result substantiates the need to explore further multimodal communication during postictal states.

We tentatively attribute these modulations of performance to a postictal verbal impairment. The Sketch model, as well as GPT, propose that the "communicative load" is divided between the verbal and gesture channels [17]. In the case of aphasia, to compensate an impairment of the verbal channel, the entire communicative load shifts to the gesture channel, resulting in an increase of co-speech gesture productions. A focus on the data from patients with LT shows a quantitative pattern that is consistent with this model. Other authors have hypothesized distinct contributions of co-speech gestures depending on their semantic role (i.e. the meaning they convey). According to the "lexical facilitation model", lexical access in speech production is facilitated by "lexical gestures", defined as "co-speech gestures that are not deictic, symbolic, nor motor gestures" [18, 32]. While there are disparities in gesture classifications across the linguistic literature, this definition of "lexical gestures" seems to be closer to our definition of rhythmic gestures (especially Butterworth gestures) than to our definition of illustrative gestures. Thus, in the context of this model, the increased proportion of rhythmic gestures we observed could be related to an attempt at easing lexical retrieval processes.

Broadening the scope beyond the current data, the interpretation that increased rhythmic gestures are linked and perhaps help ease lexical deficits can be compared with evidence showing an impact of beats on the narrative skills of children [33]. Beats are gestures defined as small up-and-down movements that, in our classification, were included in the rhythmic category (Table 3). Igualada et al. (2017) reported a task during which participants visualized a cartoon that they were then asked to recount. Among two groups, one watched a video of a person telling a different story without moving her hands and without beats, while the second group watched the same person telling the same story with accentuated beats. In the post-test, participants recounted a new visualized cartoon. The results showed a greater score of narrative structure for the group exposed to beats than for the other group. Interestingly, the group trained with beats also showed a better speech flow. These data highlight the role of beats and rhythmic gestures to ease narration and communication. Other studies have focused 
on determining what types of co-speech gestures are preferentially produced by patients with aphasia [34]. There is evidence for various types of co-speech gesture production patterns, depending on the type and the severity of aphasia. Patients with non-fluent aphasia produce more iconic gestures, pantomimes and emblems; conversely, patients with fluent aphasia use more beat gestures, compared to a control population [34].

There are some limitations in our study, including the disparity in number of frontal versus temporal seizures. In the population of patients with focal epilepsy, 35\% present drugresistance and not all of them show postictal language deficits [2]. Furthermore, a drastic inclusive criterion of our study is to select only adult patients with clinically identified language impairments after seizures. In addition, some studies caution us on the difficulty of comparing patients with in left temporal and left frontal epilepsy postictal aphasia. It has been previously shown that patients with epilepsy foci in the left frontal lobe without spread to temporal lobe in dominant hemisphere retrieve linguistic skills faster, after a seizure, than patients with dominant temporal lobe epilepsy[8]. Like in many other clinical studies, we found notable variability in our population in terms of the etiology of epilepsy, the manifestation of postictal aphasia, the duration of seizures and the duration of naming retrieval. We also note that our experimental design does not provide a conclusive test for either model of gesture production. Our aim was rather to provide a preliminary empirical exploration of the information provided by gestures about postictal language impairment and, in turn, about EZ localization. Finally, the practical challenges involved in testing complex multimodal language production during the short-lived (from almost 1 to 15 min depending on patients) with postictal states must be underscored.

The strengths of our study include an innovative multimodal description of language impairments during postictal aphasia in patients with epilepsy. Information about communication in postictal states is very sparsely available in the literature. This is despite the fact that the issue has a major interest both in clinical and neurocognitive aspects. On the one hand, a better comprehension of the semiology of seizures and postictal states might ultimately give a better comprehension of the patients' deficits and a better localization of their EZ, providing a supplementary cue to distinguish temporal from frontal origin of seizures. On the other hand, the opportunity of contrasting communication patterns in interictal versus postictal states allows keeping the same individual as their own controls, thus circumventing potential biases (e.g. vocabulary, cultural, education disparities [15]) that may stem in studies involving comparisons between healthy participants and patients. Finally, if it were confirmed, a facilitative role of co-speech gestures during language difficulties could be Fasola et al. 
harnessed in the context of multimodal language therapies, especially taking in account the available evidence on the enhancement of language skills by co-speech gesture realization (for example in language learning) [11, 15, 34, 35].

In conclusion, our study shows a significant increase of rhythmic gesture production in the postictal states, and a numeric trend for decreased verbal flow. There was no detectable difference between the performance of patients with EZ in LT or LF. The hypothesis that temporal and frontal lobe seizures induce different changes in communicative patterns than temporal seizures therefore requires further scrutiny. Beyond this preliminary report, further research should explore in more depth and quantify the nature of multimodal communication during postictal states. Despite their transient and highly constrained nature, we believe postictal states have the potential to be an informative model for communication skills as well as a relevant time-window for clinical explorations.

\section{Competing interests statement:}

No potential conflict of interest was reported by the authors. 
A description of verbal and gestural communication during postictal aphasia

\section{Reference list:}

[1] Bartha-Doering, L., \& Trinka, E. (2014). The interictal language profile in adult epilepsy. Epilepsia , 1512-1525.

[2] Baciu, M., \& Perrone-Bertolotti, M. (2015). What do patients with epilepsy tell us about language dynamics? A review of fMRI studies. Rev. Neurosciences .

[3] Trebuchon, A., Lanbert, I., Giusiano, B., McGonigal, A., Perot, C., Bonini, F., et al. (2018). The different patterns of seizure-induced aphasia in temporal lobe epilepsies. Epilepsy \& Behavior , 256264.

[4] Bancaud, J. (1975). Remarques à propos de quelques concepts de l'Electrophysiologie clinique. Revue d'Electroencéphalographie et de Neurophysiologie Clinique , 142-151.

[5] Fisher, R. S., \& Schachter, S. C. (2000). The Postictal Sate: A Neglected Entity in the Management of Epilepsy. Epilepsy \& Behavior , 52-59.

[6] Krauss, G., \& Theodore, W. H. (2010). Treatment strategies in the postictal state. Epilepsy and Behavior , 188-190.

[7] Privitera, M., \& Kim, K. K. (2010). Postictal language function. Epilepsy and Behavior , 140-145. [8] Goldberg-Stern, H., Cahill, N., \& Privitera, M. (2004). Language dysfunction after frontal lobe parietal seizures. Neurology, 1637-1638.

[9] McNeill, D. (1992). Hand and mind : What gestures reveal about thought. Chicago and London: The University of Chicago Press.

[10] Butterworth, B., \& Hadar, U. (1989). Gesture, speech, and computational stages: a reply to McNeill. Psychological Review , 168-174.

[11] Tellier, M. (2010). Faire un geste pour l'apprentissage: Le geste pédagogique dans l'enseignement précoce. In C. Colette, L'enseignement des langues étrangères à l'école (pp. 31-54). L'Harmattan. [12] Feyereisen, P. (2006). How could gesture facilitate lexical access? Advances in SpeechLanguage Pathology , 128-133.

[13] Hogrefe, K., Ziegler, W., Weidinger, N., \& Goldenberg, G. (2012). Non-verbal communication in severe aphasia: Influence of aphasia, apraxia, or semantic processing? Cortex , 952-962.

[14] Hogrefe, K., Ziegler, W., Weidinger, N., \& Goldenberg, G. (2013). Gestural expression in narrations of aphasic speakers: redundant or complementary to the spoken expression? Proceedings of the conference Tilburg Gesture Research Meeting (TIGER) .

[15] Carlomagno, S., Zulian, N., Razzano, C., De Mercurio, I., \& Marini, A. (2013). Coverbal gestures in the recovery from severe fluent aphasia: a pilot study. Journal of Communication Disorders, 84-99.

[16] Kong, A. P.-H., Law, S.-P., Wat, W. K.-C., \& Lai, C. (2015). Co-verbal gestures among speakers with aphasia: Influence of aphasia severity and semantic skills, and hemiplegia on gesture employment in oral discourse. Journal of Communication Disorders, 88-102.

[17] McNeill, D., \& Duncan, S. (2000). Growth points in thinking-for-speaking. In D. McNeill (Ed.), Language and gesture (pp. 141-161). Cambridge: Cambridge University Press.

[18] de Ruiter, J. P., \& de Beer, C. (2013). A critical evaluation of models of gesture and speech production for understanding gesture in aphasia. Aphasiology .

[19] Krauss, R. M., Chen, Y., \& Gottesmann, R. F. (2000). Lexical gestures and lexical access: A process model. In D. McNeill, Language and Gesture (pp. 261-283). Cambridge: Cambridge University Press.

[20] Kita, S., Alibali, M. W., \& Chu, M. (2017). How do gestures influence thinking and speaking? The Gesture-for-Conceptualization Hypothesis. Psychological review , 1-22.

[21] Yang, J., Andric, M., \& Mathew, M. M. (2015). The neural basis of hand gesture comprehension: A meta-analysis of functional magnetic resonance imaging studies. Neuroscience and biobehavioral reviews, 88-104.

Fasola et al. 
Fasola et al.

[22] Marstaller, L., \& Burianova, H. (2015). High gamma oscillations in medial temporal lobe during overt production of speech and gestures. PlosOne .

[23] Mastaller, L., \& Burianova, H. (2015). A common functional neural network for overt production of speech and gesture. Neuroscience, 29-41.

[24] Arthuis, M., Valton, L., Régis, J., Chauvel, P., Wendling, F., Naccache, L., et al. (2009).

Impaired consciousness during temporal lobe seizures is related to increased long-distance corticalsubcortical synchronization. Brain , 2091-2101.

[25] Tellier, M. (2012). Former à l'étude de la gestuelle: réflexions didactiques. La corporalité du langage. Aix-en-Provence: Presses Universitaires de Provence.

[26] Tellier, M. (2014). Quelques orientations méthodologiques pour étudier la gestuelle dans des corpus spontanés et semi-contrôlés. Discours .

[27] Tellier, M., Guardiola, M., \& Bigi, B. (2011). Types de gestes et utilisation de l'espace gestuel dans une description spatiale: méthodologie de l'annotation. Ateliers DEGELS .

[28] Feyereisen, P. (1982). Temporal distribution of co-verbal hand movements. Ethology and Sociobiology, 1-9.

[29] Santos, F. (2010, Mars 12). Le kappa de Cohen: un outil de mesure de l'accord inter-juges sur des caractères qualitatifs. Retrieved Juin 5, 2016, from http://www. pacea. u-bordeaux1.

fr/IMG/pdf/Kappa_Cohen. Pdf

[30] Tellier, M., Azaoui, B., \& Saubesty, J. (2012). Segmentation et annotation du geste:

Méthodologie pour travailler en équipe. JEP-TALN-RECITAL (pp. 41-55). Grenoble: ATALA \&

AFCP.

[31] Trebuchon-Da Fonseca, A., Guedj, E., Alario, F.-X., Laguitton, V., Mundler, O., Chauvel, P., et al. (2009). Brain régions underlying word finding difficulties in temporal lobe epilepsy. Brain , 27722784.

[32] Rauscher, F. H., Krauss, R. M., \& Yihsiu, C. (1996). Gesture, speech, and lexical access: The role of lexical movements in speech production. Psychological Science, 226-231.

[33] Igualada, A., Esteve-Gibert, N., \& Prieto, P. (2017). Beat gestures improve word recall in 3- to 5year-old children. Journal of Experimental Child Psychology , 99-112.

[34] Sekine, K., \& Rose, M. L. (2013). The relationship of aphasia type and gesture production in people with aphasia. American Journal of Speech-Language Pathology , 662-672.

[35] Zimmer, H. D., Engelkamp, E. (1985). An attempt to distinguish between kinematic and motor memory components. Acta Psychologica. 58, 81-106. 


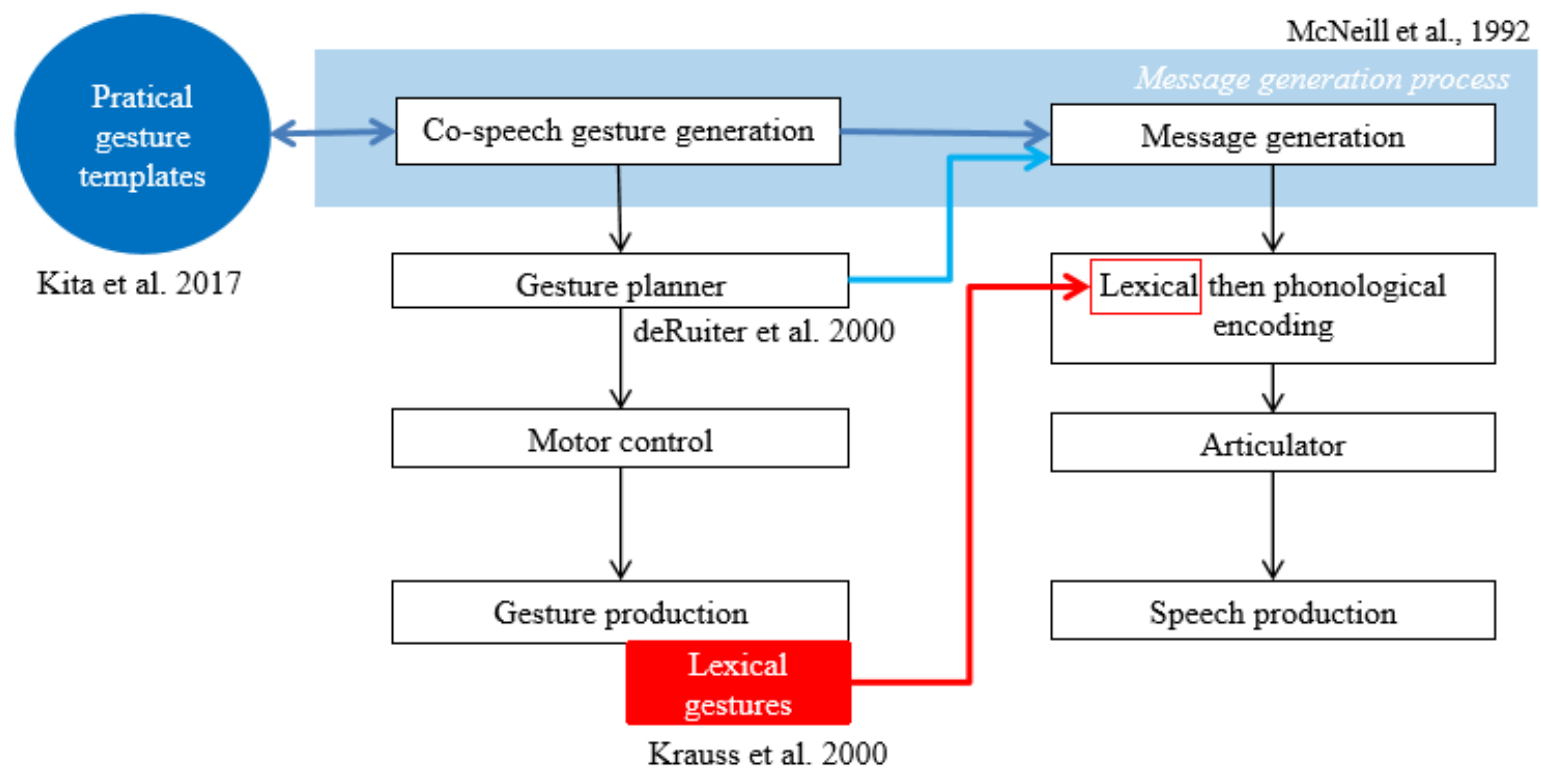

Figure1: Schematic representation of three theoretical frameworks that describe the relationship between speech and co-speech gestures. The blue area represents the idea that co-speech gestures and speech belong to a unique communication system supported by McNeill et al. Dark blue elements schematize Kita et al theoretical framework in which cospeech gestures are thought to be generated on the same basis than practical gesture. Light blue elements represent the gestural compensatory mechanism during verbal difficulties or impairments postulated by deRuiter et al. Red elements show gestural compensatory during verbal deficits postulated by Krauss et al. (in colors) 
Fasola et al.

\begin{tabular}{|c|c|c|c|c|c|c|c|c|c|c|}
\hline 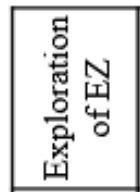 & 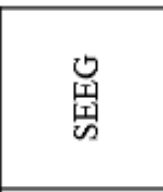 & 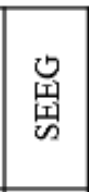 & $\begin{array}{l}\text { y } \\
\text { 跔 }\end{array}$ & 䔰 & $\begin{array}{l}\text { प्ञ } \\
\text { 愛 }\end{array}$ & 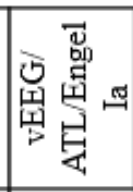 & 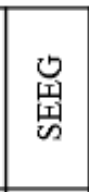 & $\begin{array}{l}\text { 㐍 } \\
\text { 等 }\end{array}$ & 怘 & 谣 \\
\hline 임 & 兊 & $\stackrel{\infty}{\sim}$ & $\stackrel{\circ}{\circ}$ & 志 & ప & 死 & $\hat{\varrho}$ & $\stackrel{\infty}{\infty}$ & I & $\vec{\sigma}$ \\
\hline$\stackrel{\circ}{g}$ & 丞 & $\bar{\sigma}$ & $\stackrel{\infty}{n}$ & 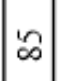 & $\stackrel{\varrho}{\varrho}$ & 乨 & $\stackrel{\infty}{\infty}$ & รั & $\bowtie$ & \% \\
\hline 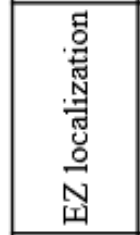 & $\begin{array}{l}\text { 吾 } \\
\text { 总 } \\
\text { 点 }\end{array}$ & 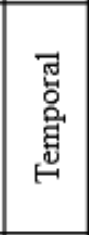 & $\begin{array}{l}\text { 焉 } \\
\text { 总 } \\
\text { 点 }\end{array}$ & 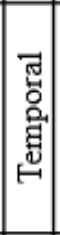 & 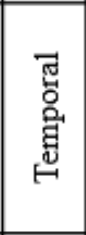 & 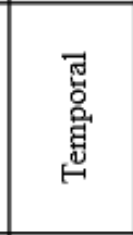 & $\begin{array}{l}\text { 점 } \\
\text { 言 } \\
\text { 总 }\end{array}$ & 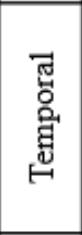 & 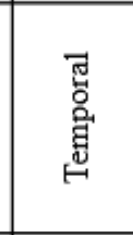 & 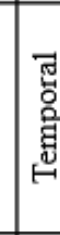 \\
\hline 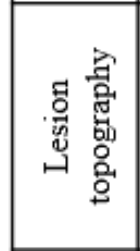 & 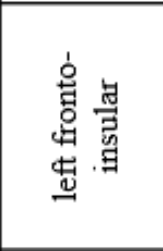 & 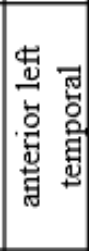 & 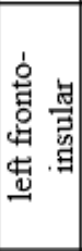 & 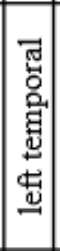 & 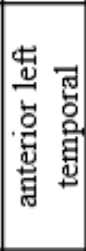 & 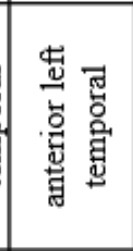 & 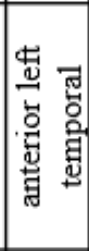 & 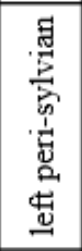 & 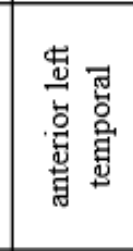 & 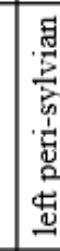 \\
\hline 莞 & 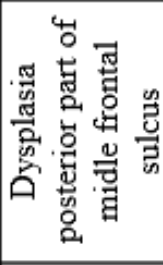 & 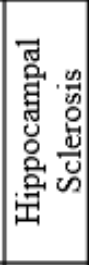 & 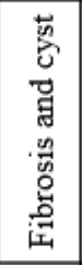 & 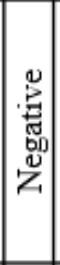 & $\begin{array}{l}\text { 总 } \\
\text { 总 } \\
\text { 岂 }\end{array}$ & 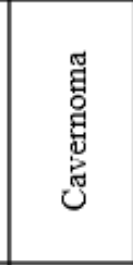 & 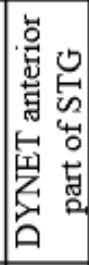 & 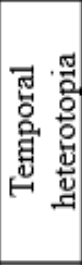 & 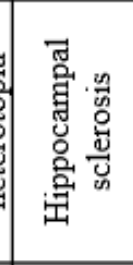 & 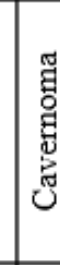 \\
\hline 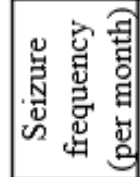 & $\begin{array}{c}\infty \\
\stackrel{8}{n} \\
\text { in }\end{array}$ & $m$ & $\begin{array}{c}\text { 密 } \\
\text { 苛 } \\
\text { m } \\
\text { m }\end{array}$ & 이 & 嵒 & 유 & $N$ & 至 & $\stackrel{\text { m }}{\stackrel{3}{-1}}$ & $N$ \\
\hline 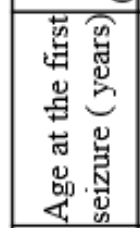 & $m$ & $\rightarrow$ & m & $\vec{v}$ & ন & $\hat{n}$ & $\approx$ & - & $n$ & m \\
\hline 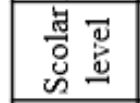 & - & $N$ & $N$ & $m$ & $\rightarrow$ & $\neg$ & $m$ & $m$ & $\sim$ & $m$ \\
\hline $\begin{array}{ll}\text { 菁告 } \\
\text { 焉 }\end{array}$ & 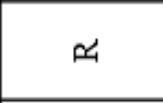 & 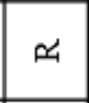 & બ & $\propto$ & $\mapsto$ & ه & $\alpha$ & $\sim 4$ & $\propto 4$ & $\alpha$ \\
\hline 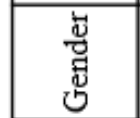 & 山 & $\Sigma$ & $\Sigma$ & $\Sigma$ & $\Sigma$ & 山 & 山 & 山 & $\Sigma$ & $\Sigma$ \\
\hline 品 & $\vec{\lambda}$ & 6 & " & $\stackrel{2}{2}$ & 合 & 合 & m & $\stackrel{\sim}{\sim}$ & $\stackrel{\infty}{\sim}$ & 움 \\
\hline 是 & $\vec{n}$ & $\tilde{\text { sิ }}$ & $\hat{n}$ & 去 & $\stackrel{n}{n}$ & $\stackrel{0}{\circ}$ & $\hat{n}$ & $\stackrel{\infty}{\circ}$ & $\stackrel{2}{2}$ & $\frac{\circ}{2}$ \\
\hline
\end{tabular}

Table 1: Patients' demographics and clinical information. Schooling: $1=$ below undergraduate degree ; 2 = high school diploma; 3 = university or schools in higher education VIQ and PIQ are verbal and non-verbal abilities scores, respectively, extracted from neuropsychological record 


\begin{tabular}{|c|c|c|c|c|c|c|}
\hline An & $\begin{array}{c}\text { Number of } \\
\text { analyzed } \\
\text { seizure }\end{array}$ & Seizure & $\begin{array}{c}\text { Seizure } \\
\text { duration } \\
(\mathrm{s})\end{array}$ & $\begin{array}{c}\text { Testing } \\
\text { delay } \\
(\text { min })\end{array}$ & $\begin{array}{c}\text { Ictal } \\
\text { aphasia }\end{array}$ & $\begin{array}{c}\text { Ictal loss of } \\
\text { consciousness }\end{array}$ \\
\hline \multirow{3}{*}{$\mathrm{P} 1$} & \multirow{3}{*}{3} & S1 & 60 & 2.5 & \multirow[b]{3}{*}{ yes } & \multirow[b]{3}{*}{ yes } \\
\hline & & S2 & 90 & 2.5 & & \\
\hline & & S3 & 60 & 2.5 & & \\
\hline $\mathrm{P} 2$ & 1 & S1 & 60 & 2.5 & no & yes \\
\hline \multirow{2}{*}{$\mathrm{P} 3$} & \multirow{2}{*}{2} & S1 & 90 & 2 & \multirow[b]{2}{*}{ no } & \multirow[b]{2}{*}{ no } \\
\hline & & $\mathrm{S} 2$ & 90 & 2 & & \\
\hline \multirow{3}{*}{$\mathrm{P} 4$} & \multirow{3}{*}{3} & S1 & 120 & 5 & \multirow[b]{3}{*}{ yes } & \multirow[b]{3}{*}{ yes } \\
\hline & & $\mathrm{S} 2$ & 90 & 5 & & \\
\hline & & S3 & 60 & 7.5 & & \\
\hline \multirow{2}{*}{ P5 } & \multirow{2}{*}{2} & S1 & 60 & 2 & \multirow[b]{2}{*}{ no } & \multirow[b]{2}{*}{ no } \\
\hline & & $\mathrm{S} 2$ & 180 & 7 & & \\
\hline \multirow{2}{*}{ P6 } & \multirow{2}{*}{2} & S1 & 120 & 5 & \multirow[b]{2}{*}{ yes } & \multirow[b]{2}{*}{ yes } \\
\hline & & S2 & 120 & 5 & & \\
\hline $\mathrm{P} 7$ & 1 & S1 & 60 & 7.5 & yes & no \\
\hline \multirow{3}{*}{ P8 } & \multirow{3}{*}{3} & S1 & 60 & $<5$ & \multirow[b]{3}{*}{ no } & \multirow[b]{3}{*}{ no } \\
\hline & & $\mathrm{S} 2$ & 120 & $<5$ & & \\
\hline & & S3 & 60 & $<5$ & & \\
\hline P9 & 1 & S1 & 114 & 5 & yes & yes \\
\hline $\mathrm{P} 10$ & 1 & $\mathrm{~S} 1$ & 140 & 15 & yes & yes \\
\hline
\end{tabular}

Table 2: Information about seizures.

S1 refers to the first seizure of a patient; S2 and S3 refer to the second and third seizures, when available. Seizure duration (in seconds) is the period between the first epileptic manifestations and the end of the ictal period, as assessed by an expert neurologist (AT). Testing delay (in minutes) is the duration between the beginning of the seizure and the start of post-ictal testing. The ictal loss of consciousness is clinically defined by the nurses during ictal testing. 


\begin{tabular}{|c|c|c|c|}
\hline $\begin{array}{c}\text { Main co-speech } \\
\text { gesture } \\
\text { categories } \\
\end{array}$ & $\begin{array}{l}\text { Detailed co- } \\
\text { speech gesture } \\
\text { categories } \\
\end{array}$ & Definition & Example \\
\hline \multirow[t]{4}{*}{ Illustrative } & Iconic & $\begin{array}{l}\text { Illustrate a concrete concept like } \\
\text { physical features of an object or an } \\
\text { action }\end{array}$ & $\begin{array}{l}\text { Speaker takes his right index finger } \\
\text { from up right. turn left and down } \\
\text { left. He says "to slide upon } \\
\text { toboggan". }\end{array}$ \\
\hline & Metaphoric & $\begin{array}{l}\text { Illustrate an abstract concept like } \\
\text { presenting a group or a concept } \\
\text { hold in a hand }\end{array}$ & $\begin{array}{l}\text { Speaker does a circle in horizontal } \\
\text { plane with his right hand and says « } \\
\text { everyone ». }\end{array}$ \\
\hline & Pointing & $\begin{array}{l}\text { Pointing is defined by } \\
\text { distinguishing two categories : } \\
\text { concrete pointing to an object in } \\
\text { the current environment or abstract } \\
\text { pointing to an object not in the } \\
\text { environment of the speaker }\end{array}$ & $\begin{array}{l}\text { The right hand comes from resting } \\
\text { position in down left to up right. It } \\
\text { is closed but the index finger is } \\
\text { extended. In the meantime. subject } \\
\text { says "there's a chandelier". }\end{array}$ \\
\hline & Emblem & $\begin{array}{l}\text { Conventional and cultural gestures. } \\
\text { Its structure is shared by a } \\
\text { population and its meaning } \\
\text { depends on the culture of the } \\
\text { interlocutor. }\end{array}$ & $\begin{array}{l}\text { Extending the index finger and the } \\
\text { middle finger by saying «both } » .\end{array}$ \\
\hline \multirow[t]{4}{*}{ Rhythmic } & Beat & $\begin{array}{l}\text { No semantic content. They are } \\
\text { rhythmic gestures like small up and } \\
\text { down movements }\end{array}$ & $\begin{array}{l}\text { The right hand is on left forearm. It } \\
\text { goes on left and return to its initial } \\
\text { position. In the meantime, the } \\
\text { subject says "that's it." }\end{array}$ \\
\hline & Butterworth & $\begin{array}{l}\text { Gestures of lexical search } \\
\text { appearing when subject do not find } \\
\text { a word. It looks like small pats or } \\
\text { frictions between index finger and } \\
\text { thumb }\end{array}$ & $\begin{array}{l}\text { The right hand is on the table. } \\
\text { Subject taps index and middle } \\
\text { fingers. The movement produces a } \\
\text { sound like "toc." Subject says "how } \\
\text { is that called." }\end{array}$ \\
\hline & Aborted & $\begin{array}{l}\text { Started gestures but aborted. } \\
\text { Subject begins his gesture and his } \\
\text { word or sentence but is interrupted } \\
\text { or his speech is impaired. Gesture } \\
\text { is in preparation stage but fails in } \\
\text { its peak }\end{array}$ & $\begin{array}{l}\text { A sentence is started: "after there's } \\
\text { the little boy. I think. which shows } \\
\text { the cat who goes on the *." In the } \\
\text { meantime, the right hand goes up } \\
\text { from its rested position and failed to } \\
\text { achieve its trajectory. }\end{array}$ \\
\hline & Other & \multicolumn{2}{|c|}{$\begin{array}{l}\text { Gestures do not belong to any categories. They may be interactive } \\
\text { gestures }\end{array}$} \\
\hline
\end{tabular}

Table 3: Categories of co-speech gestures and their definitions.

The examples are from the current data-set, translated from 
French

\begin{tabular}{|lcccccc|}
\hline An & Testing & Picture & $\begin{array}{c}\text { Verbal } \\
\text { flow } \\
\text { (words/s) }\end{array}$ & $\begin{array}{c}\text { Number of } \\
\text { gestures }\end{array}$ & $\begin{array}{c}\text { Number of } \\
\text { illustrative } \\
\text { gestures }\end{array}$ & $\begin{array}{c}\text { Number of } \\
\text { rhythmic } \\
\text { gestures }\end{array}$ \\
\hline P2 & S0 & 1 & 3 & 27 & 14 & 13 \\
P2 & S0 & 2 & 3.1 & 33 & 26 & 7 \\
P2 & S1 & 1 & 2.8 & 12 & 6 & 6 \\
P4 & S0 & 1 & 2.8 & 13 & 6 & 7 \\
P4 & S0 & 2 & 2 & 22 & 8 & 14 \\
P4 & S1 & 1 & 2.7 & 11 & 4 & 7 \\
P4 & S2 & 2 & 2.4 & 9 & 3 & 6 \\
P4 & S3 & 1 & 2.5 & 17 & 9 & 8 \\
P5 & S0 & 1 & 3.5 & 15 & 6 & 9 \\
P5 & S0 & 2 & 3.2 & 46 & 32 & 14 \\
P5 & S1 & 2 & 3.4 & 47 & 23 & 24 \\
P5 & S2 & 1 & 3.6 & 29 & 17 & 12 \\
P6 & S0 & 1 & 3.7 & 18 & 10 & 8 \\
P6 & S0 & 2 & 3.6 & 26 & 15 & 11 \\
P6 & S1 & 1 & 3 & 0 & 0 & 0 \\
P6 & S2 & 1 & 2.9 & 6 & 4 & 2 \\
P7 & S0 & 1 & 2.7 & 50 & 25 & 25 \\
P7 & S0 & 2 & 2.9 & 35 & 25 & 10 \\
P7 & S1 & 2 & 2.9 & 29 & 14 & 15 \\
P8 & S0 & 1 & 3.3 & 32 & 21 & 11 \\
P8 & S0 & 2 & 3.6 & 33 & 19 & 14 \\
P8 & S1 & 1 & 2.8 & 14 & 4 & 10 \\
P8 & S2 & 1 & 3 & 63 & 32 & 31 \\
P8 & S3 & 2 & 3.3 & 77 & 31 & 46 \\
P9 & S0 & 1 & 4.1 & 1 & 1 & 0 \\
P9 & S0 & 2 & 3.2 & 14 & 9 & 5 \\
P9 & S1 & 1 & 2.7 & 2 & 0 & 2 \\
P10 & S0 & 1 & 3.3 & 14 & 9 & 5 \\
P10 & S0 & 2 & 4 & 19 & 14 & 5 \\
P10 & S1 & 1 & 2.4 & 9 & 5 & 4 \\
\hline
\end{tabular}

Table 4: Individual results.

"Testing" refers to the moment of testing: S0 = inter-ictal testing. S1, S2, and S3 = post-ictal testing following seizures $\mathrm{n}^{\circ} 1,2$, and 3 (in gray)

"Verbal flow" and "Number of gestures" are obtained from ratings performed in ELAN (see text for details). 
Fasola et al.

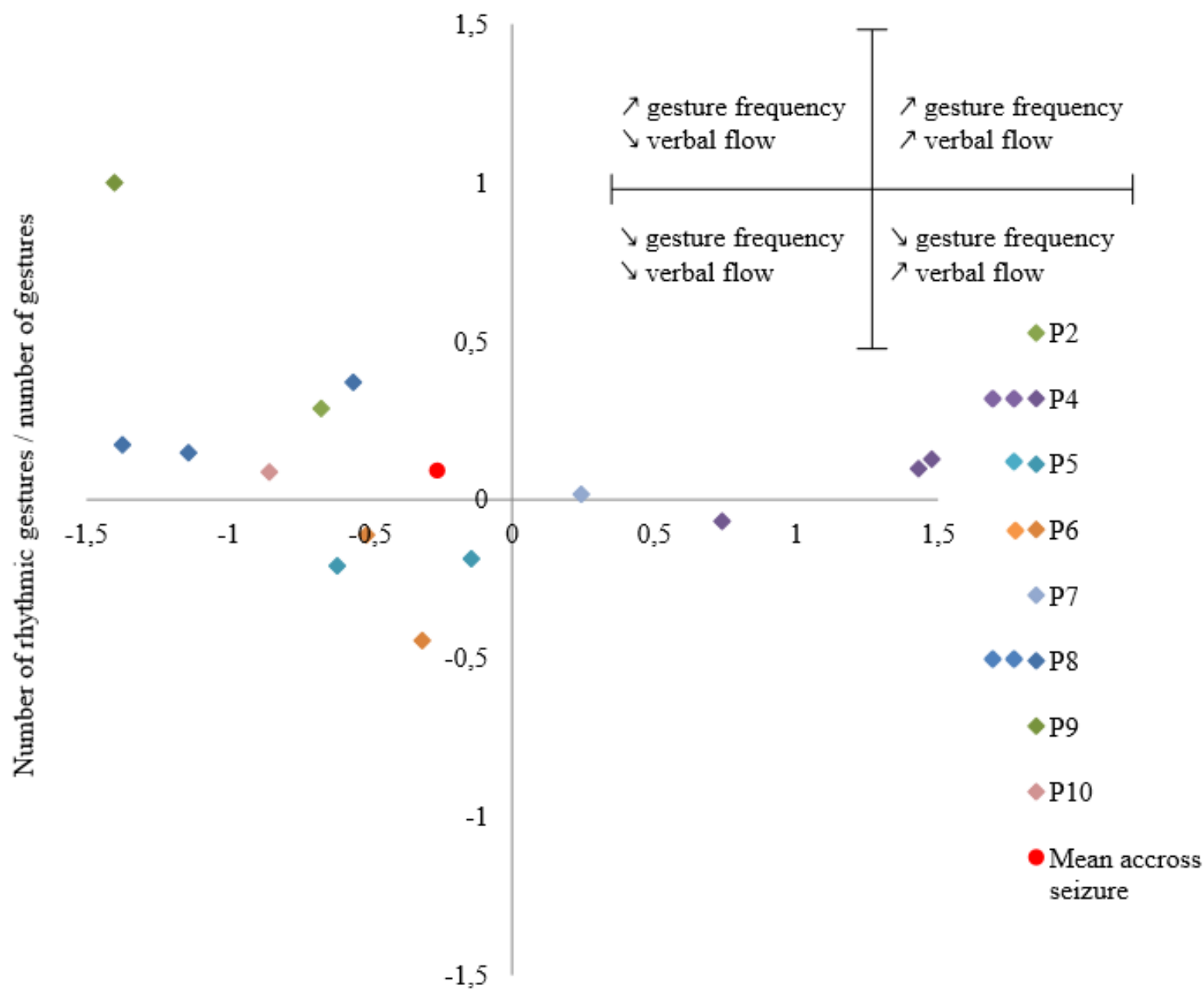

Verbal flow (word/second)

Figure 2: Frequency of rhythmic gestures in post-ictal aphasia for LT seizures. Performance is represented as the difference between interictal and postictal conditions. Each point represents a seizure and colors denote patients. The number of diamond symbols represents the number of seizures per patient; due to clinical circumstances patients do not have the same number of tested seizures. The red dot represents mean values for all seizures. (in colors) 


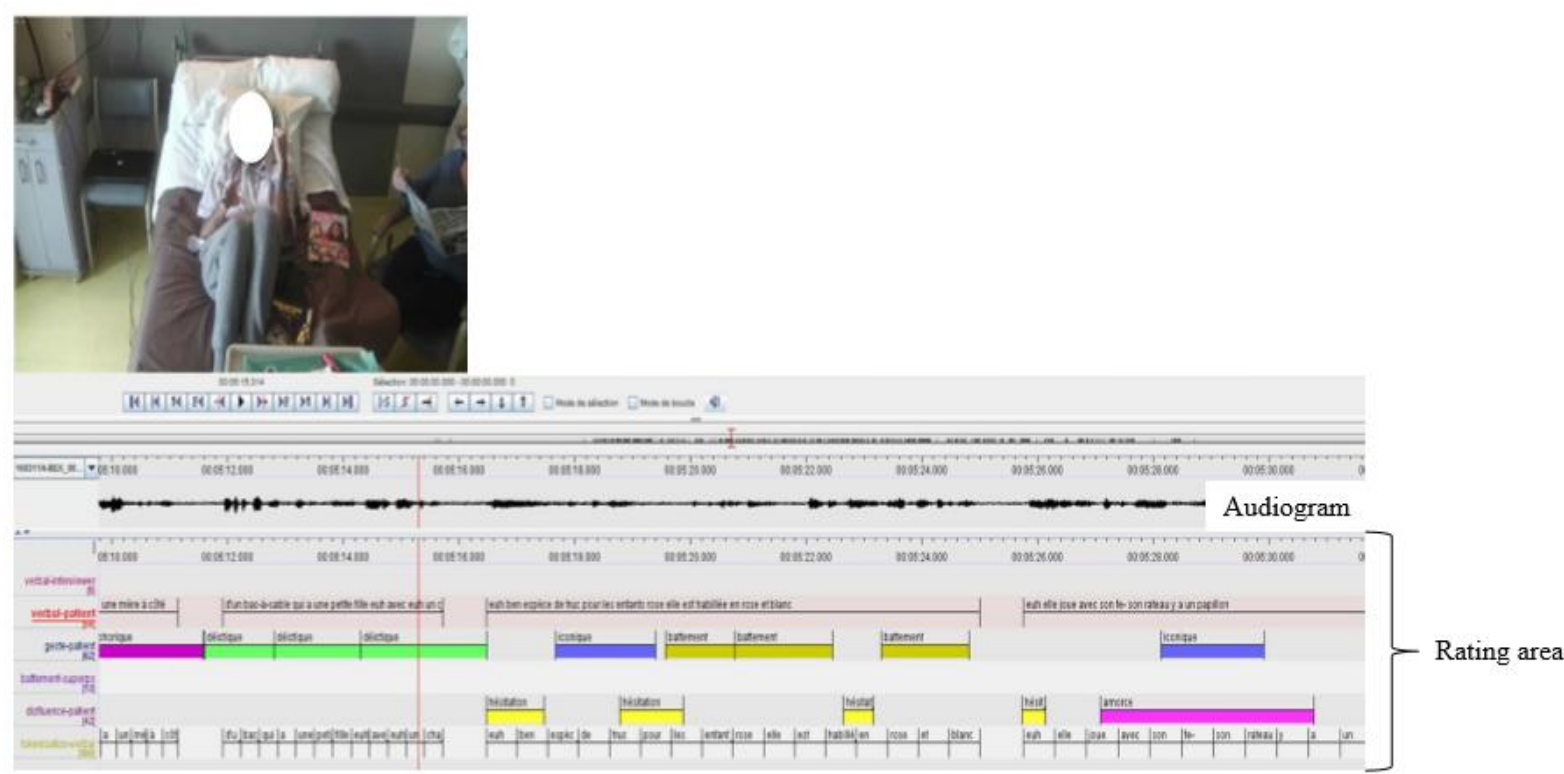

Supplementary material 1: Illustration of the ELAN's software interface for multi-modal language assessment. The two first rows are dedicated to verbal transcription. The two following rows allow co-speech gesture rating. The fifth row is dedicated to verbal dysfluencies. The last row is generated automatically by ELAN for counting words. 
Fasola et al.

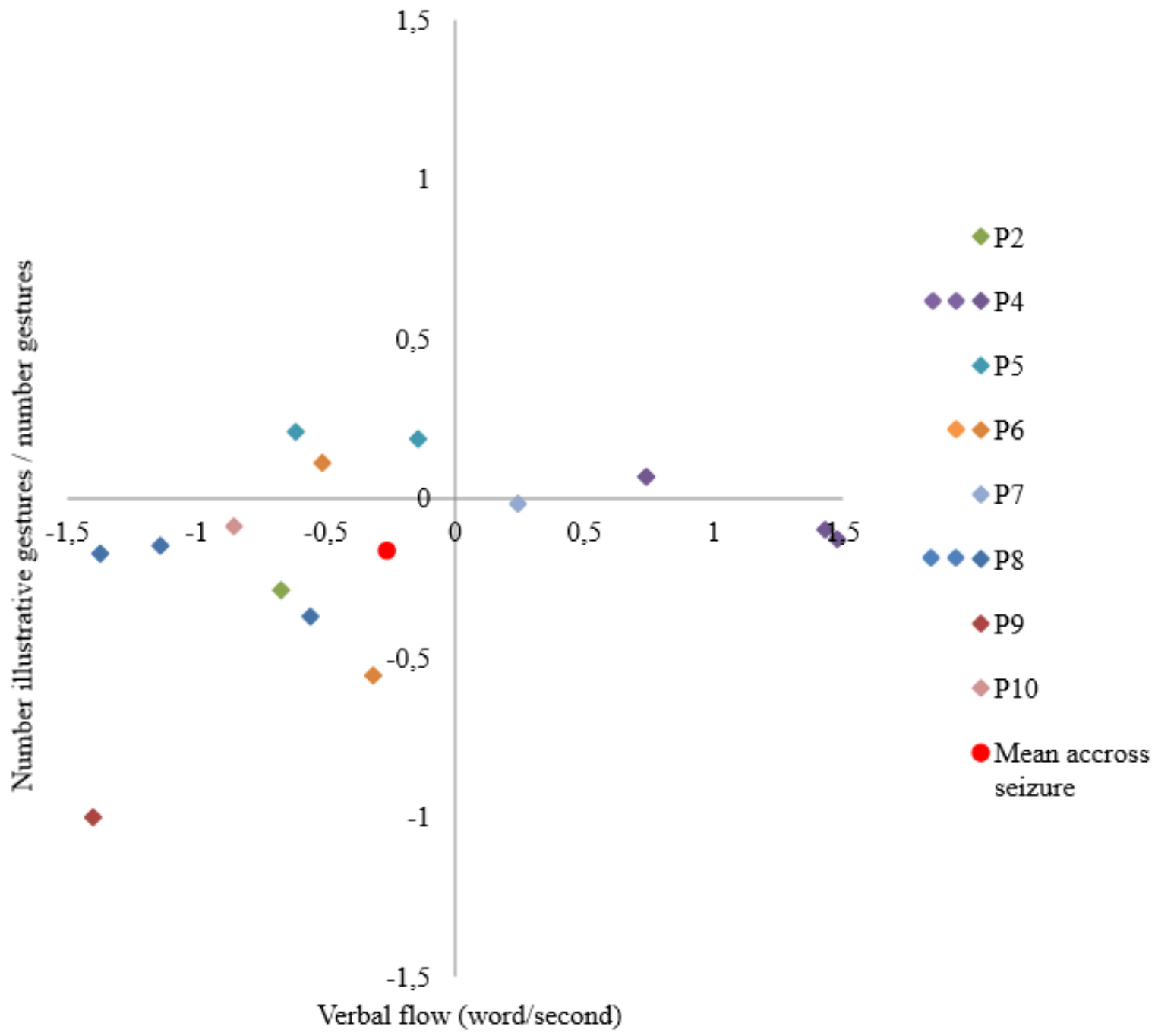

Supplementary material 2: Frequency of rhythmic gestures in post-ictal aphasia for LT seizures. Performance is represented as the difference between interictal and postictal conditions. Each point represents a seizure and colors denote patients. Because of clinical circumstances patients do not have the same number of tested seizures. The number of diamond symbols represents the number of seizure per patient. The red point represents mean values for all seizures. 
A description of verbal and gestural communication during postictal aphasia

\begin{tabular}{|ccccccc|}
\hline An & Testing & Picture & $\begin{array}{c}\text { Verbal } \\
\text { flow } \\
\text { (words/s) }\end{array}$ & $\begin{array}{c}\text { Number of } \\
\text { gestures }\end{array}$ & $\begin{array}{c}\text { Number of } \\
\text { illustrative } \\
\text { gestures }\end{array}$ & $\begin{array}{c}\text { Number of } \\
\text { rhythmic } \\
\text { gestures }\end{array}$ \\
\hline P1 & S0 & 1 & 2.6 & 3 & 3 & 0 \\
P1 & S0 & 2 & 2.7 & 6 & 5 & 1 \\
P1 & S1 & 1 & 2.8 & 5 & 3 & 2 \\
P1 & S2 & 1 & 2.7 & 3 & 1 & 2 \\
P1 & S3 & 1 & 2.3 & 6 & 2 & 4 \\
P3 & S0 & 1 & 2.1 & 49 & 17 & 32 \\
P3 & S0 & 2 & 2.2 & 72 & 38 & 34 \\
P3 & S1 & 1 & 2.2 & 10 & 6 & 4 \\
P3 & C2 & 2 & 2.3 & 17 & 8 & 9 \\
\hline
\end{tabular}

Supplementary material 3: Outcomes obtained by patients with frontal lobe epilepsy A. Individual results : "Testing" refers to the moment of testing: S0 = inter-ictal testing. S1, S2, and $\mathrm{S} 3$ = post-ictal testing following seizures $n^{\circ} 1,2$, and 3 (in gray) ; "Verbal flow" and "Number of gestures" are obtained from ratings performed in ELAN.

B. Frequency of rhythmic gestures in post-ictal aphasia: Performance is represented as the difference between interictal and postictal conditions. Each point represents a seizure and colors denote patients. Because of clinical circumstances patients do not have the same number of tested seizures. The red point represents mean values for all seizures. 